O artigo se propóe a pensar a constituição do sujeito a partir do campo do Outro, em particular a partir da relação com os objetos e do que Jacques Lacan nomeou objeto at Trataremos da relaçào com - Outro na constituição da realidade, em especial a relaça com a realidade na psicose.. Diferentemente da neurose, constata-se na psicose uma ausencia da função paterna c conseqüentemente ausencia do que Lacan, em 1966, designou como operaçĩo de extraçĩo do objeto a. Por fim, pensaremos a relaçio do autismo com o Outro e algu. mas possibilidades de direção do tratamento. Observamos que o problema do autista c menos um bloqueio no processo de humanização do que um cxcesso, sentido como invasão, da relação do sujcito com o Outro.

Psicanálise; sujeito; realidadc; altcridade; psicose c autismo

THE CONSIITUTION OF THE SUBJECT AND. THE OIHERNESS CONSIDERATIONS REGARDING PSYCHOSIS AND AUIISM

The article has as at tar. get the subject constitution study from the point of vicw of the Other's ficld, especially concerning the relationship with the objects and with what Lacan named as object a. Wo will deal with the relationship of the Other in the constitution of reality, and in particulat, the relation of reality within psychosis. In a different way of what happens with neurosis, it is shown that, concerning psychosis, there is an absence of the function of the fither, thas the absence of what Lacan, in 1966, called "operation of the extraction of the object a". Finally, it will be desling with the relationship of autism with the Other and with some possible treatment issues. We noted that the autistic problem is less than a blockage in humanization process; in fact, it is an cxcess which is felt as an invasion - of the relationship between subject and the Other. Psychoanalysis; subject; reality; otherness; psychosis and autism

\section{A CONSTITUIÇÃO DO SUJEITO E A ALTERIDADE: CONSIDERAÇÕES SOBRE A PSICOSE E O AUTISMO}

“...

u poderia sugerir que a termina por romar uma espécie de função de metáfora do sujeito do gozo. Isso não seria justo senão na medida mesma em que a fosse assimilável a um significante, mas, justamente, é o que resiste a essa assimilação à função do significante. É bem por isso que a simboliza o que, na esfera do significante, é sempre o que se apresenta como perdido, como o que se perde à significantização. Ora, é justamente esse dejeto, essa queda, o que resiste à significantização, que vem a se constituir no fundamento como tal do sujeito desejante, não mais o sujeito do gozo, mas o sujeito, na medida em que sobre na via da sua procura, enquanto goza, que não é procura de gozo, mas é o querer fazer entrar esse gozo no lugar do Outro, como lugar do significante, é aí nessa

Doutora (PUC-RJ) e professora adjunta do Curso de PósGraduação em Teoria Psicanalítica do Instituto de Psicologia da Universidade Federal do Rio de Janeiro. 
via, que o sujeito se precipita, se antecipa como desejante" (Lacan, J., Seminário X, Lição de 13 de março de 1963).

A partir dessa definição de Lacan do objeto que ele nomeou a, gostaríamos de pensar, primeiramente, a relação do objeto na constituição do sujeito e, em um segundo momento, a função do objeto na psicose e na clínica dos sujeitos ditos "inconstituídos"1.

\section{O OBJETO, O CAMPO DO OUTRO NA CONSTITUIÇÃO DO SUJEITO}

De uma maneira geral, podemos afirmar que o objeto para psicanálise designa o campo do Outro, isto é, campo de heterogeneidade em relação ao sujeito. Essa definição geral vale desde o objeto dito auto-erótico até o objeto amoroso propriamente dito, isto é, a uma escolha objetal.

Se analisarmos o que Freud designou como objeto anaclítico, objeto paradigmático da passagem da pulsão de autoconservação para a pulsão sexual (Freud, 1905), constatamos que mesmo o seio, como esse primeiro objeto, aponta, do ponto de vista do sujeito a advir, para algo heterogêneo, inassimilável, irredutível a uma satisfação completa ou a algo que possa fazer unidade tanto do ponto de vista biológico como do ponto de vista psíquico. É por essa razão que Lacan (1964) afirma que o seio só se torna objeto no momento do desmame ou que "o objeto a minúsculo não é a origem da pulsão oral. Ele não é introduzido a título de alimento primitivo, é introduzido pelo fato de que nenhum alimento jamais satisfará a pulsão oral, senão contornando-se o objeto eternamente faltante" (p. 170).

Ora, essa falta imanente à noção de objeto se torna ainda mais evidente se analisarmos o campo do amor, isto é, campo que implica para o sujeito uma escolha objetal, ou seja, momento onde o sujeito, ao menos como imagem corporal, já está constituído, uma vez que pressupōe o narcisismo - narcisismo definido como "fase", na constituição do sujeito, intermediária entre o dito autoerotismo c a escolha objetal.

No campo da vida amorosa, Freud (1914, p. 107) assinala dois tipos de escolha: um tipo que ele denomina anaclítico e, um outro, narcísico. Assim, uma pessoa pode amar em conformidade com o segundo tipo se ela amar a si mesma, ou o que ela própria foi, ou o que ela própria gostaria de ser (ideal) ou alguém que foi uma vez parte dela mesma (o filho). Em conformidade com o tipo 
anaclítico, a pessoa ou ama segundo o modelo da mulher que a alimenta ou do homem que a protege. $\mathrm{O}$ interessante desses dois tipos de escolha é que aparentemente não se trata de uma verdadeira dicotomia, pois, ao menos à primeira vista, o tipo anaclítico poderia ser incluído no tipo de narcisismo, já que não há algo mais narcísico ${ }^{2}$ do que a mãe que alimentou e o lugar do pai como aquele que protege. Entretanto, acreditamos que não foi por acaso que Freud insistiu, também em relação à escolha amorosa, em apresentar uma dicotomia e uma dialética. Pensamos que uma das razões de Freud em deixar dicotômico, dialético, em tensão, o campo do amor é que mesmo se nesse campo o sujeito está por definição em busca de uma completude (o amor como a busca do mito de Aristófanes, da metade que o completa), há algo logicamente que se apresenta como uma incompletude. Se pensarmos em termos lógicos, o campo do amor pressupõe também por definição uma perda: seja, em referência ao mito, a perda da metade que nos completa, seja porque o amor, como afirma Lacan (1964), é uma significação e como toda significação já está no campo do que não se apresenta, mas se representa, isto é, do que se representa porque está ausente como presença. Nesse sentido, mesmo que o amor seja do campo do imaginário, ou do que chamamos ilusório, ele pressupõe como toda estrutura um inapreensível para formar a unidade da imagem, ou em termos da lógica de Lacan, para que haja um todo (no caso, o amor) é necessário um não-todo. Esse 
não-todo formando o todo do amor são, em termos das escolhas amorosas apresentadas por Freud, respectivamente, a escolha anaclitica e a escolha narcísica. Ou em outras palavras, para que o amor seja a busca do mesmo (escolha narcísica) foi necessário Freud postular, recorrendo à biologia da época, a idéia de algo supostamente fora do campo sexual do amor, a saber, a idéia de apoio ou do objeto anaclítico.

Mas por que recorrer, em 1914, à idéia de algo (o campo da necessidade) que se apresenta no cerne de um pensamento já "superado" pelo próprio Freud, qual seja, a teoria sexual baseada na dicotomia entre o sexual e a autoconservação? Pensamos que a autoconservação designa, nessa apropriação, menos o apoio à biologia (alimentação) do que um recurso para apresentar algo que "escapa" ao sexual. Notamos que o verbo escapar está entre aspas, pois esse campo que, em uma primeira instância, constitui uma relação de "exceção" ao sexual, na realidade, constitui imanentemente, como não-todo do sexual, o campo do sexual. Esse dito não-sexual, Freud, através da leitura de Lacan, nomeou escolha conforme o tipo anaclítico e o sexual (o que busca a completude), escolha narcísica. E se entendermos o sexual como investimento no campo do Outro, diríamos que, nesse campo, algo escapa que nos impede de fazer unidade, esse algo é o objeto como heterogeneidade cujo paradigma Freud designou como o objeto anaclítico.

Segundo Jacques Alain Miller (1991), a oposição que Freud propõe em Introdução ao narcisismo (1914) entre o amor narcísico e amor anaclítico corresponderia respectivamente, de um lado, o amor definido como o mesmo e, do outro, como amor ao Outro, com O maiúsculo, isto é, Outro, propriamente simbólico. Segundo esse autor, essa dicotomia apontaria para uma outra mais fundamental, a saber, a dicotomia entre dois tipos de alteridade: primeiramente, uma alteridade referida a um Outro produto de um desamparo fundante (o que Freud nomeou pelo termo alemão Hilflosigkeit) e, secundariamente, uma alteridade que apontaria para a dependência (Abhängigkeit) do amor. Esse Outro associado ao desamparo corresponderia a um campo da necessidade e por essa razão pressupõe um Outro que supostamente preencheria algo (segundo o modelo paradigmático do instinto). Esse Outro dito primordial apontaria, portanto, a um Outro supostamente completo. Já a segunda alteridade correlacionada com o campo da dependência do amor supõe imanente ao campo do mesmo, isto é, do narcisismo, algo logicamente faltoso. É por essa razão que no campo do amor existe uma dupla vertente: a da busca do semelhante (demanda do Outro) e do que o Outro não tem. 
A partir dessas considerações sobre o objeto e a vida amorosa na constituição do sujeito, poderíamos colocar algumas questões: a estrutura da linguagem se impõe para qualquer ser falante como alteridade? Como podemos situar os sujeitos ditos inconstituídos? Poderia um sujeito se constituir sem uma relação de alteridade com o campo do Outro? Onde podemos situar o Outro para o caso da psicose e do autismo?

\section{A PSICOSE E A REALIDADE}

Lacan, na nota de rodapé de 1966 adicionada ao texto De uma questão preliminar a todo tratamento possível da psicose, afirma que, para que o triângulo da realidade se constitua como lugar-tenente da fantasia, é necessária a extração do objeto a. Essa extração do objeto deu origem ao esquema $R$, esquema que topologicamente se apresenta para explicitar a estrutura da realidade na neurose. Em oposição ao esquema $R$, se supôs que o esquema próprio da psicose, o esquema I, prescindiria da dita "extração do objeto a" para constituir sua realidade. Nesse sentido, a primeira questão que se impõe para pensar a relação da psicose com a realidade é saber o que vem a ser tal "extração do objeto a" - extração sem a qual o ser falante parece não constituir tal como no esquema $R$ o lugar-tenente da fantasia.

Se retomarmos com mais detalhe o esquema $R^{3}$ desse artigo de Lacan, veremos que o campo da realidade, segundo a topologia que se apresen$t a$, se define entre quatro elementos que têm sua origem no cruzamento do campo do imaginário com o campo do simbólico.

Do lado do imaginário, há o eu e a imagem, ou aquilo que, no sistema $\mathrm{L}$ representava a relação narcísica entre a (o ideal ou a imagem especular) e a'(eu) - plano que se constitui do lado do sujeito na referência fálica, isto é, o $J$. Do lado do simbólico, há o Ideal do eu e o significante do objeto primordial, que têm como terceiro elemento na posição do Outro, o Nome-do-Pai. Se esse campo da realidade, segundo Lacan, "só funciona tapando-se com a tela da fantasia”, devido à referência fálica, no caso do psicótico seria difícil definir esse campo em todas suas funções: com a foraclusão do Nome-do-Pai (este sendo assinalado pela letra $P$ de pai no esquema $R$ ), o psicótico perderá, no nível do imaginário, a referência do falo $(\Phi)$, na medida em que este se define pela seta que sai, assim como no esquema L, de A (lugar da lei) ou, no esquema $\mathrm{R}$, o Nome-do-Pai, na direção do sujeito (\$).

$\mathrm{Na}$ falta dessa dupla referência, do lado do simbólico o Nome-doPai, e do lado do imaginário o falo, o que, no esquema $R$ formaria "topologicamente" um quadrângulo da realidade, abre-se pela ausência dos pontos de referencia desses cumes. No esquema $R$, a metáfora paterna é o que desdobra o lugar do Outro em M (o Outro primordial, a Mãe) e P (Nome-do-Pai), e o efeito de significação do falo, o qual delimita e 
mantém o campo da fantasia (da realidade) com a qual o sujeito se abriga do real.

Retomando a nota de 1966 (publicação dos Écrits) acrescentada a esse texto de 1958, observamos que Lacan propõe uma reflexão topológica desse quadrângulo ilustrada pela banda $R$, situando o corte do Real no segmento I-M e a realidade como encobrindo esse ponto já que esse quadrângulo se estenderia sobre o triângulo imaginário. Esse encobrimento seria determinado por uma estrutura, e é o que ele propõe demonstrar com o triângulo simbólico

Esse campo simbólico, triângulo homólogo ao outro, imaginário, poderia recobri-lo, projetivamente, ao girar sobre a base I-M. Esse recobrimento apontaria para Lacan o "privilégio", ou melhor, uma sobredeterminação simbólica sobre o imaginário e sobre a realidade gerada nele. Como se nessa época o triângulo simbólico estivesse apontando os limites e as condições estruturais, significantes do devaneio, da errância imaginária pelo que a fantasia ou um campo de realidade encobre o Real. $\mathrm{Na}$ suposta ausência do simbólico, poderíamos sustentar que toda realidade seria mera alucinação de um sujeito que percebe (percipiens) sobre um Real. Entretanto, para Lacan dessa época, esse encobrimento imaginário segue uma estrutura, uma determinação simbólica e não pode ser concebido como obra de um percipiens autônomo e indiviso. É assim, que, através dos limites que delineiam esse campo da realidade, campo encobridor do corte do Real, aparecem os significantes que fazem desse pretenso percipiens um sujeito dividido.

Como sujeito afetado pelo pathos, o sujeito se projetará (o pontilhado do triângulo I indica tratar-se de uma projeção) em diversas imagens, como "eu" e como objeto. Essas projeções constituem o encobridor campo da realidade já que esta vela o Real. Segundo a nota acrescentada de 66, esse campo da realidade ao mesmo tempo que vela o Real se constitui como quadro pela extração, do objeto (a), ou seja, subtração de uma parte deste Real. (Aqui entendemos objeto a como inscrição portanto da impossibilidade do Real, isto é, uma certa perda de libido quando se constitui o campo da realidade como representação - significante - ou perda do que Lacan nomeou gozo).

Entretanto, para Lacan desse texto, no psicótico, a ausência, a rejeição (o termo freudiano é Verwerfung) ou melhor a foraclusão do Nome-do-Pai faz com que esse esquema não funcione. Conseqüentemente, para explicar a estrutura própria do psicótico, Lacan teve de instituir outro esquema, isto é o esquema $\mathrm{I}^{4}$, onde os pontos de referencia do Nome-do-Pai e do falo estão abertos. Nesse esquema, a realidade deixa de ser fechada no quadrângulo e passa a ser operada por uma construção do delírio que tem como função, de certa forma, "costurar", reconstruir esse campo da realidade, ligando os pontos do esquema $R$ na sua origem: do lado do falo, o ponto $i$ (as imagens especulares do esquema) liga-se ao eu do sujeito, e do lado do Nome-do-Pai, o ponto M (significante do objeto primordial) liga-se ao I (ideal do eu) - esquema $R$. 
Ora, embora Lacan, no início do seu ensinamento, tenha mostrado que no psicótico o A (grande Outro) está excluído enquanto portador do significante ${ }^{4}$, esse Outro não pode deixar de existir porque, como já afirma Lacan naquela época, “a partir do momento em que o sujeito fala, o Outro existe” (Lacan, 1955/ 56). Apesar da sua diferença, existe no psicótico não apenas o outro ao nível do imaginário - costuma repetir Lacan nesse mesmo seminário -, como também o Outro "com A maiúsculo sem o qual, afirma Lacan no Seminário III (sobre as psicoses), não haveria o problema da psicose” e sua significação inefável, mas eles, "os psicóticos, seriam apenas máquinas que falam” (p. 52).

Aliás, vinte e um anos mais tarde, em 1977, na "Abertura da Sessão Clínica”, Lacan afirma que, na psicose, o significante representa um sujeito para outro significante, e é possível situar ali o objeto a, assim como o "fading" enquanto cisão que se opera como efeito do choque do sujeito no campo do Outro.

Ora, se os quatro elementos estão presentes no campo da psicose, poderíamos afirmar que, mesmo sob uma forma totalmente particular - pois o campo da realidade está aberto pela dita foraclusão do Nome-do-Pai -, existe para a psicose a presença do campo do Outro como algo heterogêneo ao sujeito.

\section{ESTRUTURA CONSTITUINTE E SUJEITO CONSTITUÍDO}

Se os quatro elementos, portanto, estão presentes na estrutura de todo sujeito falante, podemos afirmar que o objeto como resto é um dos elementos necessários à estrutura prévia a todo ser falante. Esse elemento é, na verdade, produto da própria ação da estrutura da linguagem, pelo fato de a linguagem não cobrir, não representar inteiramente o vivente capaz de fala. É por essa razão, por haver algo que escapa à representação, que, para a psicanálise, a linguagem é uma estrutura não-toda, isto é, uma estrutura que, logicamente, não cobre tudo o que possa vir a representar do "ser" falante. Na realidade, esse algo que escapa a representação não se refere a nenhum objeto no nível da realidade empírica, mas uma função lógica. Essa função lógica Lacan nomeou conceitualmente de objeto a. Esse objeto designa no campo da linguagem a impossibilidade de esta tudo representar. A partir do pressuposto, da hipótese, que o vivente capaz de fala, enquanto não capturado pela linguagem, é ser de gozo, Lacan designa esse resto como resto de 
gozo e o objeto a como a alteridade estrutural que designa, no nível da linguagem, esse resto irrecuperável. Em termos de "Radiofonia” (1970), essa relação entre significante e resto de gozo na constituição do sujeito é definida pela própria estrutura significante que como processo formal "tritura", "cadaveriza" o vivente capaz de fala, transformando-o em um sujeito significante.

Entretanto, essa estrutura prévia, constituinte a todo ser falante, estrutura composta de significantes e de um resto prévio, não é suficiente para constituir um sujeito como tal. Para que o sujeito se constitua como desejante é necessária uma ação, um consentimento da parte desse sujeito frente a essa sobredeterminação já dada. Ou melhor, para que o sujeito se constitua como tal, ele deve construir a partir dessa alteridade prévia, dessa estrutura constituinte, uma realidade fantasmática que possa protegê-lo, de certa forma, da invasão desse resto, desse gozo.

Essa ação do sujeito acreditamos ser o que Lacan nomeou e demonstrou topologicamente na nota de 66 de "extração" do objeto a. $\mathrm{Na}$ realidade, é a partir dessa extração que o sujeito constitui, inventa ou admite uma não-garantia de tudo significar, de tudo vir a se completar no campo do Outro. Entretanto, essa alteridade, esse furo, no campo do Outro, apesar de, uma certa maneira, serem prévios, só têm conseqüência para constituir um sujeito como tal, quando o sujeito responde, consentindo, afirmando a perda de algo dessa estrutura que se quer, ao menos como construção suposta, completa - perda, portanto, diria Lacan, de gozo. Dito de outro modo, é somente, a posteriori, a partir do consentimento do sujeito a esse Outro, Outro constituinte como alteridade, que podemos falar de causalidade. Nesse sentido, causa não é antagônico de consentimento, uma vez que é somente a partir do consentimento que podemos falar da causa como constituição de um sujeito propriamente dito, isto é, sujeito desejante e, portanto, dividido entre o eu (moi) e aquilo que lhe escapa, entre o íntimo familiar e o estranho, entre a imagem de si e a imagem que o constitui vinda do outro. E para que esse campo do Outro tenha efeitos próprios de causa de desejo é necessário que o sujeito "admita", responda a essa alteridade esvaziando o Outro de sua plenitude, de sua garantia de gozo.

Nessa perspectiva, há duas dimensões de alteridade que se recobrem na constituição do sujeito: primeiramente uma alteridade prévia constituinte, dada pela estrutura a priori da linguagem. E secundariamente, trata-se de uma estrutura constituída, isto é, resposta do sujeito a partir desse Outro constituinte. Nesse segundo tempo, a posteriori, cabe ao sujeito construir o Outro, inventá-lo para que ele, o sujeito, possa se tornar desejante e responsável diante daquilo que the causou. 
Para a psicanálise, essa constituição em dois tempos tem como condição de possibilidade a função paterna. Essa função se refere menos ao pai da realidade (apesar de muitas vezes se encarnar nele) do que a um operador que propicia a construção de uma realidade. Essa realidade é constituída, por sua vez, a partir da operação de extração de gozo do campo do Outro dito gozador - extração do que, topologicamente, Lacan designou como extração de objeto a como aquilo que designa o irrecuperável de gozo. Nesse sentido, diferentemente do pai dito gozador - pai mítico tal como Freud definiu como o pai da horda primitiva (Totem e Tabu) - a função do pai como possibilidade de constituição do sujeito só pode operar no momento de destituição do gozo como tal. Se, como mito, os filhos esvaziaram o pai de gozo e instauraram a Lei a partir do seu assassinato, o sujeito para se constituir precisa, seguindo o mito como paradigma, destituir, a partir do princípio da impossibilidade, o pai gozador, "inventando" um pai que torne o gozo do Outro impossível, ou melhor, um pai que tem a função de "desertificar", "esvaziar" o gozo do Outro. Esse é o mito do Édipo ou o mito da castração tal como é vivenciado pelo neurótico. Entretanto, se para o neurótico é necessário constituir a sua realidade fantasmática, a partir de um esvaziamento desse Outro gozador, como podemos falar de função paterna e gozo para o psicótico?

\section{PSICOSE COMO RESPOSTA AO OUTRO}

Diante da estrutura previamente dada como não-toda - porque na sua totalidade não inscreve inteiramente o sujeito - o psicótico rejeita, recusa, como resposta, constituir uma realidade a partir de um pai não gozador, um pai que diga não ao gozo. Esse pai recusado, rejeitado, é o que Lacan designa pela conceito de foraclusão do Nome-do-Pai e concomitante a essa rejeição o psicótico inventa um Outro, um pai gozador. Se, para a neurose, o Nome-do-Pai ou função paterna é propiciado pela extração de gozo como resto, extração de objeto a, para psicose a foraclusão do Nome-do-Pai é a ausência de extração de gozo ou do que o designa, o objeto a.

Entretanto, a partir dessas considerações sobre o objeto e sua extração, seguiremos com a seguinte questão como aposta clínica a todo tratamento possível da psicose: será que com o alargamento do Nome-do-Pai a outras funções que não apenas a garantida pela 


\section{Artigo}

significação fálica tal como a resposta no mito do Édipo, a psicose, em trabalho, não poderia vir a constituir uma função paterna que, de alguma maneira, propicie a "extração do objeto" ou o esvaziamento de gozo do campo do Outro? Afinal, afirmou Lacan, em 13 de abril de 1976, no Seminário R.S.I: "o Nomedo-Pai podemos prescindi-lo, desde que façamos uso dele..." Ou dito de outra maneira: se o objeto a é o que designa o não-simbolizável do gozo impossível, o psicótico que, como afirma Lacan (1967) no "Pequeno Discurso aos Psiquiatras”, tem a sua disposição (em oposição a extração) o objeto a, como ele pode operar a invasão desse gozo já que ele não aceita a resposta paterna de circunscrever esse gozo como impossível - tal como os neuróticos? $\mathrm{Na}$ verdade, se o Nome-do-Pai é o que introduz o falus como o que designa a possibilidade de simbolizar esse gozo impossível, na ausência deste, como a função paterna poderia, de alguma maneira, operar e, conseqüentemente, proporcionar a constituição da realidade a partir e alguma extração de gozo como resto? $\mathrm{Na}$ realidade, a psicose deve ser pensada não como uma ausência de resposta a esse Outro, mas uma resposta, decisão, inefável e insondável, frente à presença desse Outro prévio. É apostando no sujeito como resposta, mesmo que sob a forma de negação frente a esse Outro, que, para finalizar, nos interrogaremos sobre o enigma do autista. O autista nos faz pensar, já que ele é o caso-limite da constituição do sujeito na sua relação com o Outro. Dito de outro 
modo, se pensarmos o sujeito como resposta ao campo do Outro, ao objeto como alteridade, nos indagamos qual é o estatuto possível do autista como sujeito - sujeito sim, pois acreditamos ser o autista uma forma de resposta extrema (já que seu esforço é anular) à presença do outro - entretanto, inconstituído, ou ainda a se constituir (já que não há "consentimento" como resposta, a posteriori, a esse Outro prévio).

\section{AUTISMO: UMA ALTERIDADE EM QUESTÃO}

No texto Traitement de l'Autre, Zenoni (1991) se pergunta se o que sofre o pequeno sujeito psicótico não é de um bloqueio no caminho da humanização, mas de um excesso de humanização. Trata-se de um excesso no sentido que, diferentemente de um sujeito que se constitui a partir da operação de extração do objeto ou do esvaziamento do campo do Outro, o sujeito dito inconstituído vive precisamente um excesso vindo desse Outro, um sem limite entre o vivo e o humano ou de uma não-delimitação do que se apropria do vivo (de la prise sur le vivant) ao circunscrever-se na dimensão que o especifica como humano.

$\mathrm{O}$ autismo nos apresenta como um enigma uma vez que nos coloca diante do seguinte impasse: como diante da alteridade própria a estrutura da linguagem, - alteridade presente desde sempre já no primeiro objeto dito anaclítico, o seio - um sujeito "responde" não reconhecendo a linguagem como tal, mas se mostrando alheio à alteridade própria do campo do Outro - Outro definido com Lacan como tesouro significante? Como um sujeito pode se apresentar rejeitando, ou tentando anular a dimensão do outro desde o momento que é introduzido a partir do objeto - objeto como o que designa a não-unidade entre o eu e o outro -, anulação esta que implica na própria anulação do sujeito como alteridade a esse objeto?

Parece-nos que o autismo documenta de forma radical que o Outro prévio, o Outro constituinte não é suficiente para que um sujeito se constitua como sujeito desejante. No autismo, a negação como resposta do Outro é tal que temos a impressão de que o campo do Outro e o campo do gozo se coincidem. Diante dessa coincidência, diante desse Outro absolutamente gozador, só resta como recurso do sujeito anular o outro como alteridade na tentativa, parece, de impedir a invasão de gozo que este lhe impõe. Entretanto, como para alguns psicóticos o delírio é uma tentativa de barrar o gozo, paradoxalmente, presenciamos no autista, pontualmente e às vezes incessantemente, tentativas de inscrição de algo que é afetado a partir do campo do Outro. É o que demostram as célebres estereotipias e ecolalias nos autistas. Trata-se de tentativas, talvez, no real, de inscrever uma diferença, mínima que seja, entre o eu e o que vem do outro. Diferente da significância onde no efeito de retroação uma significação de for- 
ma invertida, vinda do outro, faz o sujeito se representar entre dois significantes, os gestos "estereotipados" e palavras "ecolálicas" dos autistas não parecem apresentar uma mensagem de forma invertida que possam identificá-los em apelo. Diante dessa ausência de apelo, indagamos como o analista pode vir a operar em uma clínica tão radical? Trata-se de uma clínica onde não cabe ao analista ocupar o faz-de-conta (semblante) do lugar de objeto como causa de desejo, mas suportar a anulação mais radical, a anulação não apenas de um saber suposto, mas do próprio lugar vazio que causa o desejo. Entretanto, a aposta dessa clínica é de que talvez um autista em trabalho possa pontualmente barrar esse gozo ameaçador que vem de um outro estranho e familiar. Dessa forma, apostamos que, como no caso Dick de Melanie Klein, de alguma forma, do "sujeito em estado puro, inconstituído, inteirinho na realidade, indiferenciado", possa surgir alguma diferenciação entre o sujeito e o outro. Nesse fragmento de caso clínico, constatamos que é a partir da inscrição da palavra "estação" que o menino consegue, mesmo que provisoriamente, a perda de algo que possa barrar esse outro inteiramente gozador e transformar suas palavras em apelo, apelo ao outro, isto é, retorno, de alguma forma, de significação do campo do Outro. Segundo Lacan, a partir "dessa primeira célula, desse núcleo palpitante de simbolismo, M. Klein diz ter-lhe aberto as portas do inconsciente" (Lacan, 1953-54, p. 102).

Da mesma forma, constatamos "um fazer-se representar" do sujeito no exemplo narrado por Baio em "Comment un $S_{2}$ vient au $S_{1}$ ". A partir das escanções do "educador", introduziu-se para o sujeito uma diferenciação no estereotipado e indiferenciado barulho de sua caneca na vidraça. A partir dessa pequena alteridade introduzida pelo educador, o sujeito comparece (olhando e se aproximando do educador como Outro) no intervalo daquilo que já vinha fazendo como primeira tentativa de inscrição (barulho da caneca na vidraça) e um novo significante que se introduziu (S2 através da intervenção do educador). O barulho da caneca, que antes era pura tentativa de inscrição, torna-se agora, a posteriori, pela intervenção do educador, um S1 que pode vir a representar o sujeito diante do outro interventor. Na realidade, trata-se de uma clínica onde o que é cuidado é menos o sujeito autista do que o Outro em sua presença invasora. Acreditamos que é tratando o Outro, despojando-o de saber e, conseqüentemente, de gozo que o suporta, que podemos de alguma forma introduzir uma separação, mesmo que ínfima, entre o sujeito (que se quer objeto do gozo do outro) e o Outro. Eis aí, uma aposta de direção de tratamento.

Eis aí, na realidade, o autista como a alteridade absoluta de nosso saber, autista, portanto, como limite de nosso saber, saber 
demasiadamente calcado não na insondável decisão do ser, mas na busca da causalidade.

\section{REFERENCIAS BIBLIOGRÁFICAS}

Baio, V. (1992). Présentation de l'Antenne 110. In: Preliminaire. Une clinique en institution. Antenne 110, no 4.

Comment un $S$, vient ao $S_{1}$. Notaires de l'enfant autiste. In Ceredia. Ravages de la parole. Coleção Archives de Psychanalyse. Traduzido.

Baio, V. \& Kusnierek, M. Autismo: um psicótico em trabalho. Antenne 110. Traduzido.

Freud, S. (1905). Três Ensaios sobre a teoria da sexualidade. In Edição standard brasileira das obras completas de Sigmund Freud (vol.7, pp.123-250). Rio de Janeiro, RJ: Imago, 1966.

(1914). Introdução ao Narcisismo. In Edição standard brasileiral das obras completas de Sigmund Freud (vol. XIV, pp.123-250). Rio de Janeiro, RJ: Imago, 1979.

Lacan, J. (1953-54). Seminário I: Escritos Técnicos de Freud, Rio de Janeiro, RJ: Zahar Editores, 1979.

(1955-56). Seminário livro III: As

Psicoses, Rio de Janeiro, RJ: Zahar Editores, 1988.

(1957-58). De uma questão preliminar a todo tratamento possivel da psicose. In Escritos, Rio de Janeiro, RJ: Zahar Editores, 1998.

(1964). Os quatro conceitos fundamentais da psicanálise. O seminário, livro XI. Rio de Janeiro, RJ: Zahar.

(1967). Petits discours aux psychiatres (discurso não publicado oficialmente). (1970). Abertura da Seçĩo Clínica. Separata. Inédito.

(1975-76). Le Seminarire R.S.I. In

Ornicar? Bulletin périodiqque du Champ freudien. Paris: Lyse, $n \underline{\text { ex }} 2$ à 4 .
(1977). Ouverture de la Section Clinique. In Ornicar?, Bulletin Périodique du Champ Freudien, n 9, Paris: Lyse.

Conferência de Genebra sobre o sintoma. In Lacan, J. Intervencciones $y$ textos, $n^{2} 2$.

Miller, J-A. (1991). Lógicas da Vida Amorosa. Buenos Aires: Manantial.

Zenoni, A. (1991). Traitement de l'Autre. In Preliminaire, $n^{2} 3$.

\section{NOTAS}

1 Aqui nos referimos ao comentário de Lacan no Seminario I (1953-54) sobre o caso Dick de Melanie Kein. Veremos como ele se refere a esse sujeito, segundo Klein a partir de Lacan, bem "distinto dos neuróticos": "Do mesmo modo, Melanie Klein distingue Dick dos neuróticos, até na sua profunda indiferença, a sua apatia, a sua ausência. Com efeito, é claro que, nele, o que não é simbolizado é a realidade. Esse jovem sujeito está inteirinho na realidade, no estado puro, inconstituido." (Lacan, 1953-54, p. 84). Devemos levar em consideração que nesse contexto (década de 50), Lacan não tinha o conceito de real propriamente dito, real como impossivel, e, por essa razão, acreditamos que quando ele utiliza o termo "realidade" ele se refere não à realidade enquanto lugar-tenente do fantasma como utilizará em 1966 na nota de rodapé do texto "De uma questão preliminar a todo tratamento possivel da psicose", mas ao conceito do que mais tarde nomeará real.

2 Narcisismo aqui é definido no sentido radical, isto é, busca como processo onde o sujeito procura uma completude suposta, completude cujo esterétipo seria o dito narcisismo primário como imagem sem furo do sujeito com o campo do outro. 


\section{Artigo}

3 Eis o esquema $R$ em questão para podermos acompanhá-lo:

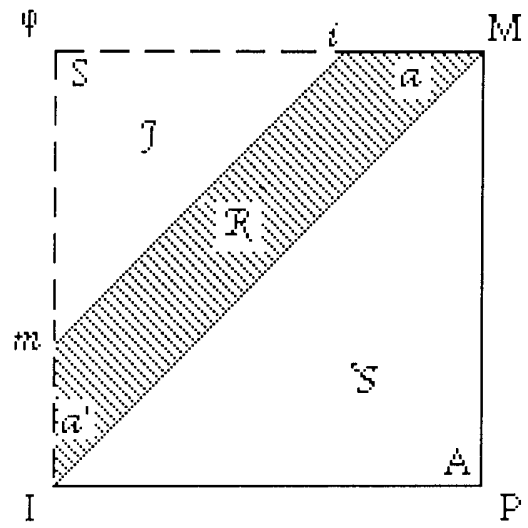

4 Recordemos também o esquema I tal como está figurado nos Écrits:

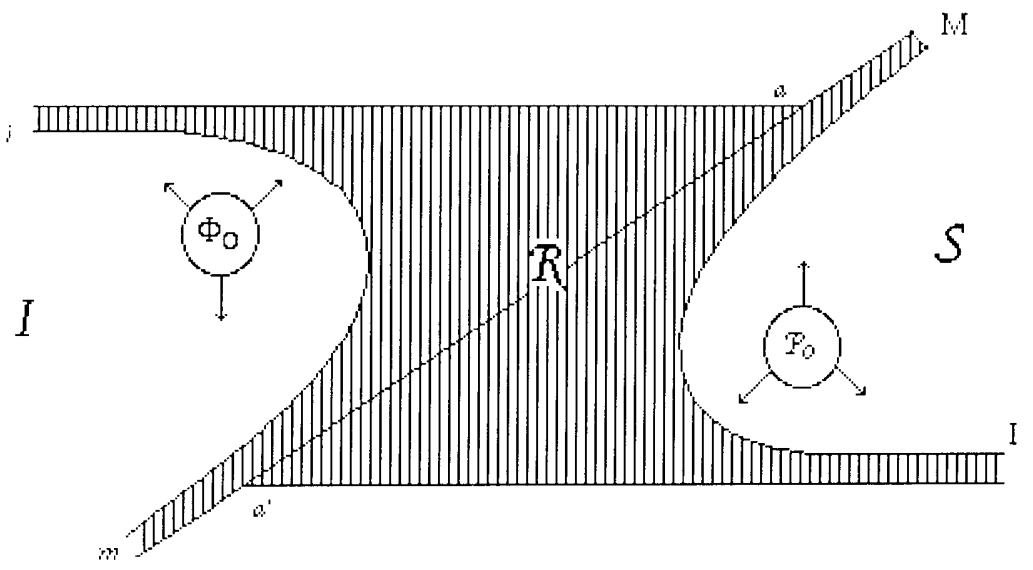

Recebido em fevereiro/2002. 